\title{
The Effects of Ankle Strengthening Training and Whole Body Vibration on the Balance of Older Adults Who Have Experienced a Fall
}

\begin{abstract}
This study observed the effects of ankle strengthening exercise and whole body vibration on the balance ability of older adults, thereby intending to provide basic materials for intervention methods aimed at improving older adults' balance ability. The subjects were 20 older adults who had experienced a fall. They were equally divided into two groups. Ankle strengthening training was applied to one group and ankle strengthening training and whole body vibration were applied to the other group, a timed up and go (TUG) test and Tinetti performance oriented mobility assessment (POMA) were performed, and changes in the subjects' limits of stability were observed. The TUG and POMA results significantly differed between before and after the experiment in the angle strengthening training (AST) group and the angle strengthening training with whole body vibration (ASTWV) group. In addition, the interaction between timing and each group was statistically significant. The limits of stability significantly changed after the intervention in both groups. Differences in the posterior and right limits of stability were significant between the AST group and ASTWV group. Therefore, ankle strengthening exercise and whole body vibration improve older adults' balance maintenance and reduce falls or the risk factors for falls in older adults.
\end{abstract}

Key words: Whole Body Vibration; Ankle Strengthening Training; Older Adults

\author{
Jung Hyun Choia, Ho Jung $\mathrm{An}^{\mathrm{b}}$ \\ ${ }^{a}$ Namseoul University, Cheonan; 'Dongnam \\ Health College, Suwon, Korea \\ Received : 9 April 2015 \\ Revised : 23 June 2015 \\ Accepted : 22 July 2015 \\ Address for correspondence \\ Ho Jung An, PT. Ph.D \\ Department of Physical Therapy, \\ Dongnam Health University, 50, \\ Cheoncheon-ro 74beon-gil, Jangan-gu, \\ Suwon-si, Gyeonggi-do, Korea \\ Tel: 82-31-249-6448 \\ E-mail: 0628jjang@hanmail.net
}

\section{INTRODUCTION}

The most considerable changes in older adults are changes in their muscles and musculoskeletal system, and this directly affects older adults' activities of daily living. In other words, older adults complain of decreased muscle strength and fatigue, and the ability of their muscles to maintain a posture degrades and their mobility decreases, with reduced functions of the internal organs and the musculoskeletal system(1). Because of such physical changes, older adults' abilities to recover balance decreases and their maximal muscle strength and response time for muscle strength generation are delayed(2). About 30\% of older adults aged 65 or older and about $50 \%$ of older adults aged 80 or older experience at least one fall per year(3).

Among the factors triggering a fall, a decrease in standing balance and mobility increases the possi- bility of a fall and 10 to $25 \%$ of all falls are related to balance decrease and gait abnormality(4). In addition, it was reported that the cause of a fall in older adults was significantly related to an increase in postural movement and decrease in dynamic balance ability $(5,6)$. A fall can occur among different forms of motion, such as initiation of gait, stopping, changing directions, and avoiding obstacles, and its major causes are confusion or disorders of vision or proprioceptive senses(1).

In older adults, a fall is the first cause of damage to the musculoskeletal system and the second cause of accident related deaths, and therefore balance exercise to prevent falls in older adults is very important(7). In order to maintain or increase older adults' muscle strength and improve their balance and gait speed, diverse exercises, including muscle strengthening exercise, flexibility training, aerobic exercise, and gait training, are useful(8). 
Mills reported that aerobic exercise of low intensity was useful for improving muscle strength, flexibility, and balance in older adults who stay home(9). Gardner et al. noted that muscle strength retraining, balance retraining, and Tai chi dramatically decreased a fall or the risk for a fall(10). Carmeli et al.(1997) reported that when muscle strengthening exercise and balance exercise were applied to older adults who stay home, the exercise group's damage from a fall decreased more than the control group's(11). Recently, diverse intervention methods as well as such exercises were studied in order to enhance older adults' balance ability $(12,13)$.

Whole body vibration exercise is essentially neuromuscular training that may improve the morphological, functional development, and physiological factors of the muscle fiber itself(14). Whole body vibration exercise may be implemented in various postures on a board where mechanical stimulation occurs. Sjehentopf et al. reported that the activation degree and areas differed according to the vibration of certain frequencies and that when tactile receptors were stimulated, the cerebral cortex and certain areas of the subcortex structure were activated(15). The present study observed the effects of ankle strengthening exercise and whole body vibration on the balance abilities of older adults, thereby intending to provide basic materials for intervention methods aimed at improving older adults' balance ability.

\section{METHODS}

\section{Subjects}

This study involved 20 older adults living in $\mathrm{H}$ Sanitarium, Yongin City, who had experienced a fall.

The selection criteria of the subjects were as follows.

A. Those who had not experienced a fall in the last year.

B. Those who could walk longer than $5 \mathrm{~m}$ independently.

C. Those who did not take medication that affects balance ability.

D. Those who had no neurological or musculoskeletal system abnormality that may trigger imbalance and a fall.
E. Those whose score of the Korean version of the mini mental state examination was 20 points or higher. Their physical characteristics are shown in Table 1.

Table 1. General features of research subjects

\begin{tabular}{|c|c|c|}
\hline & AST(Mean $\pm S D)$ & ASTWV(Mean $\pm S D)$ \\
\hline Age (y) & $61.89 \pm 7.14$ & $62.47 \pm 5.23$ \\
\hline Height $(\mathrm{cm})$ & $162.81 \pm 6.04$ & $160.14 \pm 5.31$ \\
\hline Weight (kg) & $59.36 \pm 6.73$ & $61.14 \pm 5.37$ \\
\hline MMSE & $26.47 \pm 3.47$ & $27.27 \pm 4.14$ \\
\hline
\end{tabular}

\section{Experimental Procedures}

The 20 older adults who had experienced a fall were equally divided into two groups: one group conducted ankle strengthening exercise, and ankle strengthening exercise and whole body stimulation were applied to the other group. The ankle strengthening training group(AST) did an ankle exercise program three days per week for six weeks. The training consisted of exercises performed in standing positions on a hard floor; the exercises were performed using an aero step(16).

During the exercises, for ankle strengthening strategies, joint movements were consciously limited by the subject, and the therapist observed and guided the exercises when necessary. Each exercise program(1 set) was 30 minutes; there were also warm up exercises(5 minutes) before the exercise program and cool down exercises $(5$ minutes) afterward. The balance training program is shown in Table 2.

Table 2 Ankle strengthening training program

\begin{tabular}{|c|c|}
\hline Exercise Program & Time \\
\hline Warm-up exercise & 5 minutes \\
\hline \multicolumn{2}{|l|}{$\begin{array}{l}\text { An exercise performed in a standing posi- } \\
\text { tion on a stable (hard) floor }\end{array}$} \\
\hline $\begin{array}{l}\text { - Ankle strategy exercise raising the heels } \\
\text { of both feet slowly } \\
\text { - Ankle strategy exercise raising the heels } \\
\text { of both feet } \\
\text { - Ankle strategy exercise standing on one } \\
\text { leg and alternating }\end{array}$ & $\begin{array}{l}5 \text { minutes } \\
5 \text { minutes } \\
5 \text { minutes }\end{array}$ \\
\hline \multicolumn{2}{|l|}{ Exercise on an aero step } \\
\hline $\begin{array}{l}\text { - Ankle joint strategy exercise maintain- } \\
\text { ing balance in a static posture } \\
\text { - Ankle joint strategy shaking the body } \\
\text { in the anterior, posterior, left, right, and } \\
\text { diagonal directions } \\
\text { - Cool-down exercise }\end{array}$ & $\begin{array}{l}5 \text { minutes } \\
10 \text { minutes } \\
5 \text { minutes }\end{array}$ \\
\hline
\end{tabular}


The ankle strengthening training with whole body vibration(ASTWV) group conducted ankle strengthening exercise three times per week for six weeks and received whole body stimulation training twice per week. The ankle strengthening exercise was the same as that for the AST group, and for whole body stimulation training, the exercise method by Jo was referenced(reference number). A whole body vibration device was used for 10 minutes with low intensity $(24-28 \mathrm{~Hz})$ for the first one to two weeks, middle intensity $(32-36 \mathrm{~Hz})$ for the third to fourth week, and high intensity for the fifth to sixth week. A vibro wedge manufactured by NEXT was used as the whole body vibration device(17). The subjects sat upright on the whole body vibration device, maintaining the angle between the hip joint and the knee joint at 90 degrees. The applied frequency was between 10 and $30 \mathrm{~Hz}$ as was suitable for each subject's sensation conditions.

\section{Measurement Methods}

\section{TUG test}

This study employed a walking test in order to measure dynamic balance ability. This test was initiated with the subject in a sitting posture on a chair with arms on a flat ground. The subject got of the chair, traveled back and forth three meters, and sat back down. The subject repeated this motion three times, and an average time was measured(18).

\section{POMA}

This study employed a performance oriented mobility assessment in order to measure dynamic balance ability. This test was done with a hard chair and a watch only, and therefore may be easily used as a task oriented test. The balance score is 16 points and the gait score is 12 points, for a total of 28 points. The test was done three times, and the average value of the measurements was recorded(19). Interrater reliability was $\mathrm{r}=.84$.

\section{Limits of stability (LOS)}

In the present study, a HUR BT4 (HUR Labs, Tampere, Finland) was used for the LOS test. The HUR BT4 platform is an elaborate and portable piece of assessment equipment designed for improved tests of stability. The BT4 (HUR Labs) model by Apsun Inc. was used to measure through the limit of the stability of the ankle. Each subject mounted the platform with bare feet and main- tained a standing position. The equipment's screen was placed behind the subjects to prevent them from seeing the screen; the subjects tilted their bodies forward, backward, leftward, and rightward using only their ankle joints while maintaining the posture for 8 sec per direction. Each study subject was measured three times, and the average value was recorded. The sensitivity of $\mathrm{BT} 4$ is $2(\mathrm{~V} / \mathrm{V} \pm 0.25 \%)$, and the maximum range of error is $0.03 \%$.

\section{Data Analysis}

The data measured in the present study were analyzed using the SPSS ver. 18.0 program. The general features were indicated as mean values and standard deviations. Levene $\mathrm{F}$-tests were used to verify the homogeneity of the subjects, and Kolmogorov-Smirnov tests were used to prove the normal distribution. Two way repeated measure ANOVAs were conducted to compare differences in the TUG, POMA, and LOS tests, the variables between the groups(AST and ASTWV), and times (before and after the intervention). Significant differences between pre tests and post tests were verified using paired sample t-tests. The statistical significance level was set to $\alpha=.05$.

\section{RESULTS}

\section{Changes in the TUG and POMA Test Results according to Muscle Therapy during Balance Exercise}

The results of the TUG and POMA tests significantly differed between before and after the experiment in the AST group and the ASTWV group $(p\langle .05)\langle$ Table 3$\rangle$. In addition, the interaction between timing and each group was statistically significant $(\mathrm{p}<.05)$ (Table 3$)$. 
Table 3. Changes in the TUG test results within each group and differences in the results between the groups according to muscle therapy during balance exercise

\begin{tabular}{cccccc}
\hline Variable & Group & Pre M \pm SD & Post M \pm SD & & $p$ \\
\hline \multirow{2}{*}{ TUG } & AST & $21.217 \pm 6.247$ & $16.748 \pm 7.217 \dagger$ & group & .161 \\
& ASTWV & $23.475 \pm 5.147$ & $15.574 \pm 6.212 \dagger$ & time & $.000^{*}$ \\
& & & group*time & $.000^{*}$ \\
POMA & AST & $20.478 \pm 24.147$ & $24.235 \pm 2.047$ & group & .402 \\
& ASTWV & $21.017 \pm 3.214$ & $25.147 \pm 1.874$ & time & $.000^{*}$ \\
& & & group*time & $.000^{*}$ \\
\hline
\end{tabular}

${ }^{* *}$ p $<.001{ }^{*} \mathrm{p}<.05, \dagger$ Statistically significant from the pretest results,

AST: ankle strengthening training group,

ASTWV: ankle strengthening training with whole body vibration group

Changes in the Limits of Stability according to Muscle Therapy during Balance Exercise

Changes in the limits of stability were significant after the intervention compared to before the intervention in both AST and ASTWV (p<.05) 〈Table 4 . Changes in the limits of stability in the posterior and right directions were statistically significantly different between the AST group and the ASTWV group (p<.05)(Table 4).

Table 4. Changes in the Limits of Stability Within Each Group and Differences in the Values between the Groups According to Muscle Therapy during Balance Exercise

\begin{tabular}{cccccc}
\hline Variable & Group & Pre M \pm SD & Post M \pm SD & & $\mathrm{p}$ \\
\hline \multirow{2}{*}{ Anterior } & AST & $3.017 \pm 1.238$ & $4.941 \pm 0.587 \dagger$ & group & 0.074 \\
& ASTWV & $4.136 \pm 1.170$ & $5.070 \pm 0.332 \dagger$ & time & $.000^{* *}$ \\
& & & group*time & .324 \\
Posterior & AST & $3.214 \pm 0.874$ & $4.234 \pm 1.271 \dagger$ & group & $.038^{*}$ \\
& ASTWV & $2.987 \pm 0.793$ & $5.241 \pm 0.574 \dagger$ & time & $.000^{* *}$ \\
& & & & group*time & .418 \\
Left & AST & $2.983 \pm 1.247$ & $4.154 \pm 1.823 \dagger$ & group & $.040^{*}$ \\
& ASTWV & $2.572 \pm 1.058$ & $5.290 \pm 1.638 \dagger$ & time & $.001^{*}$ \\
& & & & group*time & .612 \\
Right & AST & $2.954 \pm 1.047$ & $3.547 \pm 1.634 \dagger$ & group & .067 \\
& ASTWV & $2.841 \pm 0.542$ & $4.374 \pm 0.716 \dagger$ & time & $.002^{*}$ \\
& & & & group*time & .314 \\
\hline
\end{tabular}

${ }^{* *} \mathrm{p}<.001{ }^{*} \mathrm{p}<.05$, † Statistically significant from the pretest results,

AST: ankle strengthening training group,

ASTWV: ankle strengthening training with whole body vibration group

\section{DISCUSSION}

A decrease in equilibrium ability is perceived by older adults as a major factor that increases the risk of a fall and degrades their quality of life.
Therefore, improvement in the equilibrium response related to the increased possibility of a fall in older adults is very important for preventing a fall and enhancing their quality of life(20). In a study by Balogun et al.(1994), the subjects' 
equilibrium ability was well maintained until they were in their 40s, but after their 40s, their equilibrium ability decreased. Aspeopleaged, their proprioceptive sense decreased according to physiological changes related to aging, their righting reflex became slow, and postural sway increased, making it difficult to maintain equilibrium(21). A study also concluded that 10 to $25 \%$ of all falls were related to a decrease in equilibrium and abnormal gait(22). Therefore, this study observed the effects of ankle strengthening exercise and whole body vibration on the balance ability of older adults, thereby intending to provide basic materials for intervention methods aimed at improving older adults' balance ability.

There were statistically significant changes in the TUG and POMA test results in the AST group and the ASTWV group after the intervention(Table 4). In addition, the interaction between the timing and each group was statistically significant (Table 4). Ankle joint strategies require appropriate joint range of motion and muscle strength, and typically, the lower extremities functionally demand afferent and efferent muscle activities $(23,24)$. In addition, in balance and the performance of functional tasks, the muscle strength of the instep flexor and sole flexor is important(25). A study by Ki(2001) involved 15 healthy adults. They were divided into an experimental group that conducted ankle muscle strengthening exercise and a control group that did not perform any exercise, and changes in their muscle strength, agility, and dynamic balance were observed. The experimental group's muscle strength, agility, and dynamic balance were significantly higher(26). ShumwayCook et al.(2007) applied a complex exercise program and an educational program for fall prevention to healthy elderly subjects three times per week for one year and reported that their dynamic gait ability improved. Faber et al.(2006) also applied an educational program, where ankle strengthening exercise was included, to healthy elderly subjects and observed improvement in their dynamic gait ability and muscle strength. In the present study, like in the previous research, both the AST group and the ASTWV group saw their balance ability significantly improve, because the ankle strengthening exercise enhanced the stability and flexibility of the ankle joint, affecting the equilibrium of the human $\operatorname{body}(27,28)$.

Whole body vibration increases the input of proprioceptive sense information through afferent neurons, thereby stimulating the sensory system for postural control $(29,30)$. In order to improve the proprioceptive senses affecting balance in older adults and patients with neurological system damage, vibration stimulation that stimulates the proprioceptive senses is being employed(31). Priplata et al. (2003) reported that whole body vibration stimulation applied to older adults positively affected their postural control, and Shin compared a whole vibration stimulation group and a load stimulation and whole vibration stimulation group in 34 menopausal women and observed that the second group's balance significantly improved(32, 33). In the present study, changes in the limits of stability were significant in both the AST and STEWV groups after the intervention. In addition, there were significant differences in the limits of stability in the posterior and right directions between the two groups. However, in the other directions, there were no differences between the two groups. The reason for this is that performing whole body vibration exercise for a long time decreases the influence on muscle strength with the action by nerve roots on frequency and amplitude(34). Further, in the present study, six weeks of ankle strengthening exercise sufficiently affected the stability and flexibility of the ankle joints of the AST group as well as of the ASTWV group.

\section{CONCLUSION}

Ankle strengthening exercise with whole body vibration stimulation is an intervention method that can reduce older adults' falls or risk of falls. Future research is considered necessary to observe joint flexibility or muscle strength after ankle strengthening exercise and whole body vibration stimulation to look at which factors affect balance. The subjects were 20 older adults who had experienced a fall. They were equally divided into two groups. Ankle strengthening training was applied to one group and ankle strengthening training and whole body vibration were applied to the other group, TUG test and POMA were performed, and changes in the subjects' limits of stability were observed.

1. The TUG and POMA results significantly differed between before and after the experiment in the AST group and the ASTWV group. The interaction between timing and each group was statistically significant. 
2. The limits of stability significantly changed after the intervention in both groups. Differences in the posterior and right limits of stability were significant between the AST group and ASTWV group.

Therefore, ankle strengthening exercise and whole body vibration improve older adults' balance maintenance and reduce falls or the risk factors for falls in older adults.

\section{REFERENCES}

1. Singh MM, Malhotra HS. Falls in the elderlyclinician's approach. J Indian Med Assoc 2003; 101(7): 422-424.

2. Mackey DC, Robinovitch SN. Postural steadiness during quiet stance does not associate with ability to recover balance in older women. Clin Biomech 2005; 20(8): 776-783.

3. Campbell AJ, Reinken J, Allan BC, Martinez GS. Falls in old age: a study of frequency and related clinical factors. Age Ageing 1981; 10(4): 264-270.

4. Shumway-Cook A, Baldwin M, Polissar NL, Gruber W. Predicting the probability for falls in community-dwelling older adults. Phys Ther 1997; 77(8): 812-819.

5. Campbell AJ, Borrie MJ, Spears GF. Risk factors for falls in a community-based prospective study of people 70 years and older. J Gerontol 1989; 44(4): M112-117.

6. Wolfson L, Whipple R, Amerman P, Kleinberg A. Stressing the postural response. A quantitative method for testing balance. J Am Geriatr Soc 1986; 34(12): 845-850.

7. Bonnie RJ, Fulco CE, Liverman CT. Reducing the Burden of Injury: Advancing Prevention and Treatment. Institute of Medicine (US) Committee on Injury Prevention and Control, Washington (DC): National Academies Press (US) 1999.

8. Chandler JM, Hadley EC. Exercise to improve physiologic and functional performance in old age. Clin Geriatr Med 1996 Nov;12(4):761-84.

9. Mills EM. The effect of low-intensity aerobic exercise on muscle strength, flexibility, and balance among sedentary elderly persons. Nurs Res 1994; 43(4): 207-211.

10. Gardner MM, Robertson MC, Campbell AJ. Exercise in preventing falls and fall related injuries in older people: a review of randomised controlled trials. Br J Sports Med 2000; 34(1): 7-17.
11. Carmeli E, Bar-Chad S, Lotan M, Merrick J, Coleman R. Five clinical tests to assess balance following ball exercises and treadmill training in adult persons with intellectual disability. $J$ Gerontol A Biol Sci Med Sci 2003; 58(8): 767-772.

12. Murphy C, Miller BF. Protein consumption following aerobic exercise increases whole-body protein turnover in older adults. Appl Physiol Nutr Metab 2010 ; 35(5): 583-590.

13. Elder CP, Mahoney ET, Black CD, Slade JM, Dudley GA. Oxygen cost of dynamic or isometric exercise relative to recruited muscle mass. Dyn Med 2006; 5: 9.

14. Ahlborg L, Andersson C, Julin P. Exercise in preventing falls and fall related injuries in older people: a review of randomised controlled trials. Br J Sports Med 2000; 34(1): 7-17.

15. entopf CM, Heubach K, Ischebeck A, Gallasch E, Fend M, Mottaghy FM, Koppelstaetter F, Haala IA, Krause BJ, Felber S, Gerstenbrand F, Golaszewski SM. Variability of BOLD response evoked by foot vibrotactile stimulation: influence of vibration amplitude and stimulus waveform. Neuroimage 2008; 41(2): 504-510.

16. Lee JW. Effect of ankle strategy exercise on improvement of balance in elderly with impaired balance. Unpublished doctoral dissertation, Yonsei University 2007.

17. Cho YJ. The Effect Of Whole-Body Vibration Exercise On Lower Body Muscle Function And Bone Mineral Destiny In Older Women. Unpublished doctoral dissertation, DanKook University 2010.

18. Podsiadlo D, Richardson S. The timed "Up \& Go": a test of basic functional mobility for frail elderly persons. J Am Geriatr Soc 1991; 39(2): 142-148.

19. Canbek J, Fulk G, Nof L, Echternach J. Testretest reliability and construct validity of the tinetti performance-oriented mobility assessment in people with stroke. J Neurol Phys Ther 2013; 37(1): 14-19.

20. Harada N, Chiu V, Damron-Rodriguez J, Fowler E, Siu A, Reuben DB. Screening for balance and mobility impairment in elderly individuals living in residential care facilities. Phys Ther 1995; 75(6): 462-469.

21. Balogun JA, Akindele KA, Nihinlola JO, Marzouk DK. Age-related changes in balance performance. Disabil Rehabil 1994; 16(2): 58-62.

22. Silsupadol P1, Siu KC, Shumway-Cook A, Woollacott MH. Training of balance under singleand dual-task conditions in older adults with balance impairment. Phys Ther 2006; 86(2): 269-281. 
23. Shumway-Cook A, and Wollacott MH. Motor Control: Translating Research into Clinical Practice(4ed). Lippincott Williams \& Wilkins 2011.

24. Kaminski TW, Perrin DH, Gansneder BM. Eversion strength analysis of uninjured and functionally unstable ankles. J Athl Train 1999; 34(3): 239-245.

25. Lamontagne A, Malouin F, Richards CL, Dumas F. Mechanisms of disturbed motor control in ankle weakness during gait after stroke. Gait Posture 2002; 15(3): 244-255.

26. Kim MJ. Effects of ankle muscle strengthening for preventing of falls in the elderly persons. Korean National University of Physical Education 2001.

27. Menant JC, Steele JR, Menz HB, Munro BJ, Lord SR. Optimizing footwear for older people at risk of falls. J Rehabil Res Dev 2008; 45(8): 1167-1181.

28. Alfieri FM1, Riberto M, Gatz LS, Ribeiro CP, Lopes JA, Battistella LR. Comparison of multisensory and strength training for postural control in the elderly. Clin Interv Aging 2012; 7: 11925.

29. Roll JP, Vedel JP, Ribot E. Alteration of proprioceptive message induced by tendon vibrationinman: A microneurographicstudy. Exp Brain 1989; 76: $213-222$.
30. Verschueren SM, Swinnen SP, Desloovere K, Duysens J. Vibration-induced changes in EMG during human locomotion. J Neurophysiol 2003; 89(3): 1299-1307.

31. Rittweger J, Mutschelknauss M, Felsenberg D. Acute changes in neuromuscular excitability after exhaustive whole body vibration exercise as compared to exhaustion by squatting exercise. Clin Physiol Funct Imaging 2003; 23(2): 81-86.

32. Priplata AA, Patritti BL, Niemi JB, Hughes R, Gravelle DC, Lipsitz LA, Veves A, Stein J, Bonato P, Collins JJ. Noise-enhanced balance control in patients with diabetes and patients with stroke. Ann Neurol 2006; 59(1): 4-12.

33. Shin SS. The Effect of whole body vibration with weighted vest on body composition, knee extensor strength, static standing balance and bone mineral density for postmenopausal wowen. Unpublished doctoral dissertation, Sahmyook University 2012.

34. Torvinen S, Kannu P, Sievänen H, Järvinen TA, Pasanen M, Kontulainen S, Järvinen TL, Järvinen M, Oja P, Vuori I. Effect of a vibration exposure on muscular performance and body balance. Randomized cross-over study. Clin Physiol Funct Imaging 2002; 22(2): 145-152. 